\title{
Luminescent lanthanoid complexes of a tetrazole-functionalised calix[4]arene
}

\author{
Daniel D'Alessio ${ }^{a}$, Sara Muzzioli, ${ }^{b}{\text { Brian W. Skelton, }{ }^{c} \text { Stefano Stagni, }{ }^{b} \text { Massimiliano Massi }{ }^{*}, a}^{a}$ and Mark I. \\ Ogden $*, a$
}

\author{
5 Received (in $X X X, X X X)$ Xth $X X X X X X X X X 20 X X$, Accepted Xth $X X X X X X X X X 20 X X$ \\ DOI: 10.1039/b000000x
}

p-t-Butylcalix[4]arene functionalised at the lower rim with two tetrazole moieties is found to be a useful receptor for lanthanoid cations. The luminescence of the resulting ${ }_{10}$ complexes can be controlled by addition of base, with emission achieved in the visible and infrared regions.

The tetrazole moiety has been attracting steadily increasing attention over the past few years. Much of the activity is focussed on its use as a carboxylate analogue that is not readily 15 metabolised, leading to applications in drugs that tend to have improved stability and availability. ${ }^{1}$ Tetrazole ligands will also interact with cations or anions, depending on the protonation state, leading to a potentially rich coordination / supramolecular chemistry. ${ }^{2-4} \mathrm{We}$ are interested in using the calixarene framework 20 to create ionophores for specific applications, such as lanthanoidbased luminescent species that can be incorporated into polymeric materials. ${ }^{5}$ Functionalising the lower rim of calix[4]arene is a long-standing method to form ionophores with high stability constants, ${ }^{6}$ but to our knowledge no examples 25 where the tetrazole moiety is used in place of the more common amide or ester groups have been reported (we note that a small number of upper-rim tetrazole-functionalised calixarene receptors have been reported). ${ }^{7-9}$ With respect to oxygen donor ligands, the coordination chemistry of tetrazolate anions with lanthanoid 30 cations has received significantly less attention due to the highly oxophilic nature of the f-block elements. ${ }^{10-14}$ Recently, however, a few examples of luminescent lanthanoid tetrazolato complexes have been reported, ${ }^{13,14}$ suggesting that tetrazole-functionalised calixarenes may be useful for our applications. To that end, we

35 report here the synthesis and characterisation of the bis-tetrazole substituted calix[4]arene $\mathbf{1 H}_{4}$ (Fig. 1), along with the investigation of the photophysical properties of the associated $\mathrm{Tb}$, $\mathrm{Eu}$ and $\mathrm{Nd}$ complexes. The structural characterisation of the functionalised ligand $\mathbf{1 H}_{4}$ and the corresponding $\mathrm{Eu}$ complex is 40 also presented herein.

The synthesis of $1 \mathrm{H}_{4}$ was achieved by converting the previously reported 5,11,17,23-tetra-tert-butyl-25,27dicyanomethoxy-26,28-dihydroxycalix[4]arene ${ }^{15}$ to the bistetrazole by reaction with sodium azide and triethylammonium ${ }_{45}$ chloride in toluene, according to established procedures. ${ }^{16} \dagger$ Crystals suitable for a single crystal X-ray structure determination were grown from acetonitrile, $\downarrow$ and the result confirmed the expected structure, with the calixarene in the typical cone conformation. $1 \mathrm{H}_{4}$ crystallizes with two molecules of acetonitrile, 50 one of which is included in the cavity formed by the calixarene (Fig. 2). There are intra-molecular hydrogen bonds between the hydroxyl hydrogen atoms and the oxygen atoms of the neighbouring phenoxy rings. There are also intra-molecular hydrogen bonds between the N-H hydrogen atoms of the ordered 55 tetrazolyl group $(\mathrm{H} 312)$ and between one component of the disordered tetrazolyl groups (H122) to the phenoxyl oxygen atoms. The N-H hydrogen on the other component of the disordered tetrazolyl group (H112) forms an inter-molecular hydrogen bond to the nitrogen atom of the other solvent 60 acetonitrile molecule. These interactions are shown in Fig 2 (see also Fig S-1, and Table S-2, for the relevant geometries). $\dagger$

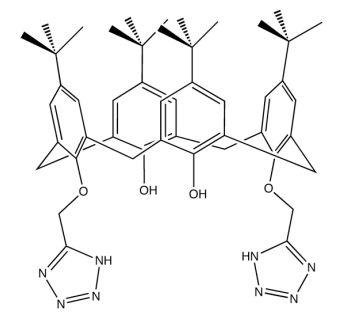

Figure 1 Structure of the calix[4]arene ligand $1 \mathrm{H}_{4}$.

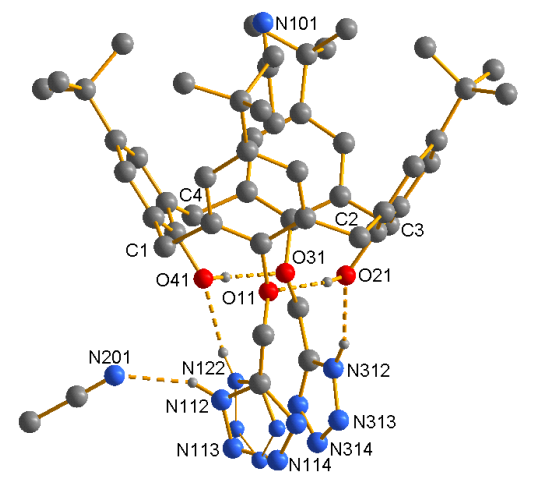

65 Figure $2 \mathrm{~A}$ view of the structure of $1 \mathrm{H}_{4} \cdot 2 \mathrm{CH}_{3} \mathrm{CN}$, showing intra- and intermolecular hydrogen bonds (ellipsoids have been drawn at the $20 \%$ probability level).

Crystallisation of the metal complexes of $\mathbf{1}$ was attempted using a range of conditions. A solution of $1 \mathrm{H}_{4}$ in dichloromethane 70 solubilised some $\mathrm{Tb}\left(\mathrm{NO}_{3}\right)_{3}(\mathrm{dmso})_{3}$ upon heating. Colourless crystals deposited upon standing, which were found to be the 
unusual species $\mathrm{Tb}\left(\mathrm{NO}_{3}\right)_{3}\left(\mathrm{H}_{2} \mathrm{O}\right)(\mathrm{dmso})_{2}$ rather than the coordinated complex. $\dagger+$ A $1: 1$ solvent mixture of acetonitrile/methanol was more successful, with suitable crystals of the $\mathrm{Eu}$ complex obtained, allowing for a structure 5 determination to be carried out. $\$$ The results are consistent with the formation of a 1:1 complex, with the Eu atom octacoordinated to the four phenol $\mathrm{O}$ atoms, two tetrazole $\mathrm{N} 1$ atoms, and two $\mathrm{O}$ atoms derived from adventitious water (Fig. 3). $\dagger$ It is clear from coordination geometries that the free phenol groups have been 10 deprotonated. As a result of disorder, hydrogen atoms were not located and it is unclear if there are hydrogen atoms on the tetrazole ligands and if the coordinated oxygen atoms are water molecules or hydroxyl groups. Thus the overall charge on the molecule is uncertain. However, there was no sign of a 15 triethylammonium cation or a nitrate anion in the structure. Hence, a neutral molecule seems the most probable formulation. The calixarene conformation differs from the pseudo 4-fold symmetry observed in the metal-free structure, being "pinched", with angles between opposite phenyl planes of $88.2(3)^{\circ}$ (phenyl 20 rings 1 and 3 ) and $12.5(3)^{\circ}$ (phenyl rings 2 and 4). Overall, the observed coordination chemistry of $\mathbf{1}$ is typical of a calixarene ionophore. To our knowledge, no metal complex of the analogous bis-carboxylate calix[4]arene has been reported to date, so a direct comparison is not possible. Similar binding modes are well ${ }_{25}$ established for bis-substituted amide and ester functionalised calix[4]arenes, including lanthanoid complexes of mixed carboxylate/(ester or amide) systems. ${ }^{17,18}$ It is notable that in many cases, the carboxylate moiety in these mixed systems bridges between two metal centres, forming dimeric structures in 30 the solid-state, ${ }^{17-19}$ which is not observed here with the bulkier tetrazole moiety.
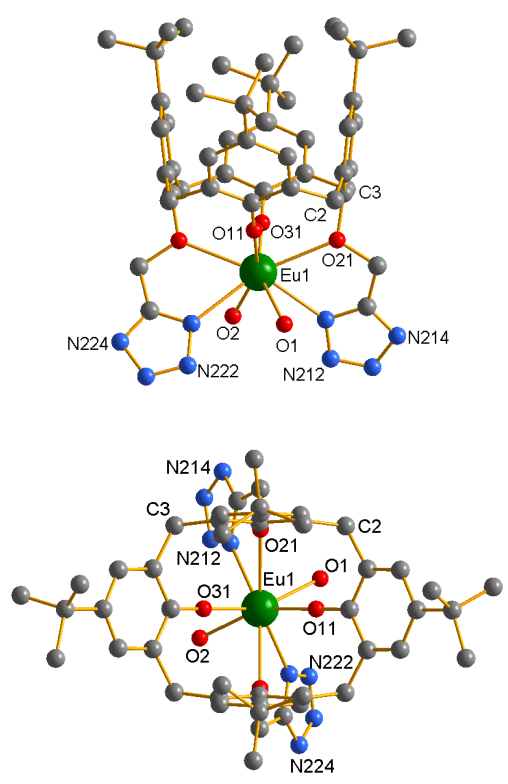

Figure 3 Simplified views of the Eu complex of 1, with one of the disordered components omitted.

The absorption profile of $\left[\mathrm{Ln}\left(\mathbf{1 H}_{4}\right)\right]\left(\mathrm{NO}_{3}\right)_{3}(\mathrm{Ln}=\mathrm{Nd}, \mathrm{Gd}, \mathrm{Eu}$, Tb, Fig. S-5) presents an intense and slightly structured band in the 260-300 $\mathrm{nm}$ region, attributed the a ${ }^{1}\left(\pi-\pi^{*}\right)$ transition centered on the phenyl rings of the calixarene system. However, a
40 contribution to this band from an analogous ${ }^{1}\left(\pi-\pi^{*}\right)$ transition centered on the tetrazole rings cannot be excluded. Upon deprotonation, a red-shifted shoulder appears in the spectrum around $300-320 \mathrm{~nm}$, assigned to the ${ }^{1}\left(\pi-\pi^{*}\right)$ transition now centered on the phenolato and tetrazolato ligands. To assess 45 whether the ligand $1 \mathrm{H}_{4}$ is suitable as an antenna for the sensitisation of lanthanoid luminescence, the phosphorescent emission of the $\mathrm{Gd}$ complex, tentatively formulated as $\left(\mathrm{Et}_{3} \mathrm{NH}\right)[\mathrm{Gd}(\mathbf{1})]$ (obtained by mixing equimolar amounts of $\mathbf{1 H}_{4}$ and $\left[\mathrm{Gd}(\mathrm{dmso})_{6}\right]\left(\mathrm{NO}_{3}\right)_{3}$ with an excess of triethylamine), was 50 recorded at $77 \mathrm{~K}$ in glassy $\mathrm{MeOH}$. The $0-0$ phonon transition for this emission, ascribed to a decay from the ${ }^{3}\left(\pi-\pi^{*}\right)$ excited state of the ligand, was estimated at $26,316 \mathrm{~cm}^{-1}$.

The emission spectrum of the Tb complex (Fig. 4), excited at $\lambda_{\text {ex }}=306 \mathrm{~nm}$, shows the characteristic line-like bands belonging ${ }_{55}$ to the ${ }^{5} \mathrm{D}_{4} \rightarrow{ }^{7} \mathrm{~F}_{\mathrm{J}}(\mathrm{J}=6,5,4,3)$ transitions, with the most intense band being the "green" ${ }^{5} \mathrm{D}_{4} \rightarrow{ }^{7} \mathrm{~F}_{5}$ at $544 \mathrm{~nm}$. Upon addition of the base, the intensity of the emitted radiation increases slightly until 4 eq. of triethylamine are added. After that, the intensity increases rapidly beginning to plateau after adding 20 eq. of base. ${ }_{60}$ The initial equivalents of base are likely to cause the deprotonation of the tetrazole ring, this being a stronger acid than phenol. This causes an increase in the intensity of the absorption shoulder at $310 \mathrm{~nm}$ with consequent increase of the emission intensity. However, the presence of the phenol $\mathrm{OH}$ might still ${ }_{65}$ cause quenching via energy transfer to the $\mathrm{OH}$ vibration modes. ${ }^{20}$ This is consistent with the observed increase in emission with continued addition of base, which is assumed to induce deprotonation of the phenol $\mathrm{OH}$ groups, reducing quenching. The excited state lifetime $(\tau)$ was fitted as a monoexponential with $\tau=$ $701.2 \mathrm{~ms}$ in aerated DCM solution, as typical of lanthanoid phosphorescent emission. Counter-intuitively, after addition of excess base, $\tau$ decreased to a value of $600 \mu \mathrm{s}$, which is tentatively ascribed to a change in the coordination sphere of the $\mathrm{Tb}$ ion with possible inclusion of water molecules. This hypothesis is 75 supported by the structure of the Eu complex (Fig. 3), where two water molecules are coordinated to the metal centre.

The emission spectrum of the Eu complex $\lambda_{\mathrm{ex}}=306 \mathrm{~nm}$ (Fig. 4) shows the characteristic line-like bands attributed to the ${ }^{5} \mathrm{D}_{0} \rightarrow$ ${ }^{7} \mathrm{~F}_{\mathrm{J}}$. The strictly forbidden $\Delta J=0{ }^{5} \mathrm{D}_{0} \rightarrow{ }^{7} \mathrm{~F}_{0}$ band does not appear 80 in the spectrum suggesting the absence of $J$ coupling. ${ }^{21,22}$ Compared to the magnetic dipole transition ${ }^{5} \mathrm{D}_{0} \rightarrow{ }^{7} \mathrm{~F}_{1}$, the hypersensitive "red" ${ }^{5} \mathrm{D}_{0} \rightarrow{ }^{7} \mathrm{~F}_{2}$ band at $614 \mathrm{~nm}$ is much more intense. The intensity of the ${ }^{5} \mathrm{D}_{0} \rightarrow{ }^{7} \mathrm{~F}_{2}$ band seems to be caused in this case by crystal field mixing, which is the main mechanism ${ }_{85}$ responsible for the relative intensity of the ${ }^{5} \mathrm{D}_{0} \rightarrow{ }^{7} \mathrm{~F}_{4}$ as well. ${ }^{21,22}$ The high intensity ratio $\mathrm{I}\left({ }^{5} \mathrm{D}_{0} \rightarrow{ }^{7} \mathrm{~F}_{2}\right) / \mathrm{I}\left({ }^{5} \mathrm{D}_{0} \rightarrow{ }^{7} \mathrm{~F}_{1}\right)$ is also indicative of emission originating from $\mathrm{Eu}$ centres in a low symmetry coordination site. ${ }^{21}$ As in the case of Tb, upon initial addition of triethylamine the intensity of the emitted radiation 90 slightly increases. However, after 4 equivalents the phosphorescence is completely quenched via a low energy ligand-to-metal charge transfer [phenolate to $\mathrm{Eu}$ (III) to yield quenched $\mathrm{Eu}(\mathrm{II})]$. The excited state lifetime of the Eu complex in air-equilibrated DCM solution is fitted as monoexponential with a 95 value of $\tau=1.2 \mathrm{~ms}$, decreasing to $\tau=800 \mu$ s upon initial addition of the base. As per the case of Tb, we ascribed the decrease in the value of $\tau$ to a hydration of the Eu cation. 

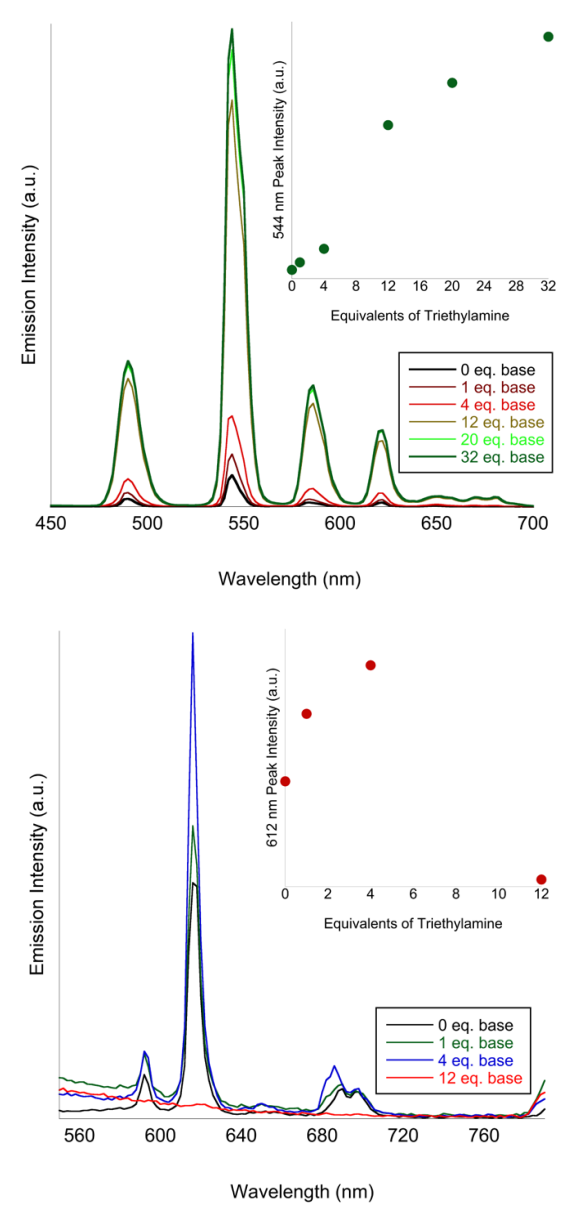

Figure 4. Emission spectra for the $\mathrm{Tb}$ (top) and $\mathrm{Eu}$ (bottom) complexes of 1 in air-equilibrated DCM, with sequential addition of triethylamine. 5 Insets: intensity progression for the $544 \mathrm{~nm} \mathrm{~Tb}$ peak (top) and the $612 \mathrm{Eu}$ peak (bottom).

The antenna effect of $\mathbf{1 H}_{4}$ was probed for the $\mathrm{Nd}(\mathrm{III})$ complex in order to achieve emission in the IR region. The resulting complex is non-emissive until a large excess of base is added, at 10 which point a feeble band at $1068 \mathrm{~nm}$ is detected (Figure S-9). The sharp peak is attributed to the fluorescent emission ${ }^{4} \mathrm{~F}_{3 / 2} \rightarrow$ ${ }^{4} \mathrm{I}_{11 / 2}$, with a characteristic excited state lifetime $\tau=16 \mu \mathrm{s}$. The weak nature of the emission is ascribed to the large difference between the ${ }^{3}\left(\pi-\pi^{*}\right)$ excited state of the ligand and the ${ }^{4} \mathrm{~F}_{3 / 2}$ state 15 of Nd. Moreover, quenching phenomena due to $\mathrm{OH}$ and $\mathrm{NH}$ vibrations, before the addition of base, and water coordination to the metal centre upon deprotonation of the ligand might contribute to the decrease in fluorescent intensity.

In conclusion, we have synthesised a tetrazole-functionalised 20 calix[4]arene that acts as an ionophore for lanthanoid cations, forming luminescent complexes. Structural characterisation of a europium complex confirms that the lanthanoid interacts with all of the available donor atoms. Work is underway to study the coordination chemistry of $1 \mathrm{H}_{4}$ in more detail, along with related 25 tetrazole-functionalised calixarene derivatives.

\section{Notes and references}

a Department of Chemistry, Curtin University, Bentley $6102 \mathrm{WA}$, Australia. Fax: +6180266 2300; Tel: +61 89266 2483; E-mail: m.ogden@curtin.edu.au,m.massi@curtin.edu.au.
${ }_{30}{ }^{b}$ Department of Physical and Inorganic Chemistry, University of Bologna, viale Risorgimento 4, 40136 Bologna, Italy.

${ }^{c}$ Centre for Microscopy, Characterisation and Analysis, M313,

University of Western Australia, Perth, WA 6009, Australia.

$\dagger$ Electronic Supplementary Information (ESI) available: synthesis and

35 characterisation of $1 \mathrm{H}$ and associated metal complexes, crystallographic data, excitation and emission profiles. See DOI: $10.1039 / \mathrm{b} 000000 \mathrm{x} /$

‡ Crystal data for $\mathbf{1 H}_{4} \cdot \mathbf{2} \mathbf{C H}_{3} \mathbf{C N}$ : $\mathrm{C}_{52} \mathrm{H}_{66} \mathrm{~N}_{10} \mathrm{O}_{4}, \mathrm{M}=895.15$, monoclinic, space group $C 2 / c, a=23.526(5), b=11.962(2), c=37.255(6) \AA, \beta=$ $110.96(2)^{\circ}, V=9790(3) \AA^{3}, Z=8, T=100 \mathrm{~K}, 71629$ reflections 40 collected, 8627 independent reflections, 5115 reflections with $(I>2 \sigma(I))$, $R 1(I>2 \sigma(I))=0.0785, w R 2$ (all data) $=0.168$. CCDC No. 851655 .

Crystal data for Eu-1: $\mathrm{C}_{48} \mathrm{H}_{61} \mathrm{EuN}_{8} \mathrm{O}_{6}, \mathrm{M}=998.01$, monoclinic, space group $C 2 / m, a=20.852(3), b=12.9596(12), c=24.4175(19) \AA, \beta=$ 103.649(11) ${ }^{\circ}, V=6412.2(11) \AA^{3}, Z=4, T=100 \mathrm{~K}, 31105$ reflections 45 collected, 7685 independent reflections, 7033 reflections with $(I>2 \sigma(I))$, $R 1(I>2 \sigma(I))=0.084, w R 2$ (all data) $=0.211$. CCDC No. 851653 .

Crystal data for $\mathbf{T b}\left(\mathbf{H}_{2} \mathrm{O}\right)(\mathbf{d m s o})_{2}\left(\mathbf{N O}_{3}\right)_{3}: \mathrm{C}_{4} \mathrm{H}_{14} \mathrm{~N}_{3} \mathrm{O}_{12} \mathrm{~S}_{2} \mathrm{~Tb}, \mathrm{M}=519.22$, triclinic, space group $P \overline{1}, a=7.9696(2), b=7.9761(2), c=13.9627(3) \AA$, $\alpha=75.947(2), \beta=87.082(2), \gamma=66.169(2)^{\circ}, V=786.47(3) \AA^{3}, Z=2, T$

$50=100 \mathrm{~K}, 35729$ reflections collected, 10211 independent reflections, 9149 reflections with $(I>2 \sigma(I)), R 1(I>2 \sigma(I))=0.024, w R 2($ all data $)=0.054$. CCDC No. 851654

1. R. J. Herr, Biorg. Med. Chem., 2002, 10, 3379-3393.

55 2. H. Zhao, Z. R. Qu, H. Y. Ye and R. G. Xiong, Chem. Soc. Rev., 2008, 37, 84-100.

3. M. V. Werrett, D. Chartrand, J. D. Gale, G. S. Hanan, J. G. MacLellan, M. Massi, S. Muzzioli, P. Raiteri, B. W. Skelton, M. Silberstein and S. Stagni, Inorg. Chem., 2011, 50, 1229-1241.

60 4. S. Stagni, S. Colella, A. Palazzi, G. Valenti, S. Zacchini, F. Paolucci, M. Marcaccio, R. Q. Albuquerque and L. De Cola, Inorg. Chem., 2008, 47, 10509-10521.

5. C. R. Driscoll, B. L. Reid, M. J. McIldowie, S. Muzzioli, G. L. Nealon, B. W. Skelton, S. Stagni, D. H. Brown, M. Massi and M. I. Ogden, Chem. Commun., 2011, 47, 3876-3878.

6. C. D. Gutsche, Calixarenes - An Introduction, Second edn., Royal Society of Chemistry, Cambridge, 2008.

7. T. Pinter, S. Jana, R. J. M. Courtemanche and F. Hof, J. Org. Chem., 2011, 76, 3733-3741.

70 8. V. Boyko, R. Rodik, O. Danylyuk, L. Tsymbal, Y. Lampeka, K. Suwinska, J. Lipkowski and V. Kalchenko, Tetrahedron, 2005, 61, 12282-12287.

9. A. Dondoni and A. Marra, Chem. Rev., 2010, 110, 4949-4977.

10. P. C. Andrews, P. C. Junk, M. Massi and M. Silberstein, Chem. Commun., 2006, 3317-3319.

11. P. C. Andrews, T. Beck, B. H. Fraser, P. C. Junk and M. Massi, Polyhedron, 2007, 26, 5406-5413.

12. A. Facchetti, A. Abbotto, L. Beverina, S. Bradamante, P. Mariani, C. L. Stern, T. J. Marks, A. Vacca and G. A. Pagani, Chem. Commun., 2004, 1770-1771.

13. M. Giraud, E. S. Andreiadis, A. S. Fisyuk, R. Demadrille, J. Pecaut, D. Imbert and M. Mazzanti, Inorg. Chem., 2008, 47, 3952-3954.

14. E. S. Andreiadis, R. Demadrille, D. Imbert, J. Pecaut and M. Mazzanti, Chem. Eur. J., 2009, 15, 9458-9476.

85 15. E. M. Collins, M. A. McKervey, E. Madigan, M. B. Moran, M. Owens, G. Ferguson and S. J. Harris, J. Chem. Soc., Perkin Trans. 1, 1991, 3137-3142.

16. K. Koguro, T. Oga, S. Mitsui and R. Orita, Synthesis, 1998, 910-914.

17. P. D. Beer, G. D. Brindley, O. D. Fox, A. Grieve, M. I. Ogden, F.

90 Szemes and M. G. B. Drew, J. Chem. Soc., Dalton Trans., 2002, 3101-3111.

18. P. D. Beer, M. G. B. Drew, A. Grieve, M. Kan, P. B. Leeson, G. Nicholson, M. I. Ogden and G. Williams, Chem. Commun., 1996, 1117-1118

95 19. F. ArnaudNeu, G. Barrett, G. Ferguson, J. F. Gallagher, M. A. McKervey, M. Moran, M. J. SchwingWeill and P. Schwinte, Supramol. Chem., 1996, 7, 215-222.

20. J. C. G. Bunzli, Chem. Rev., 2010, 110, 2729-2755.

21. M. Hilder, P. C. Junk, U. H. Kynast and M. M. Lezhnina, J. Photochem. Photobiol., A, 2009, 202, 10-20.

22. M. Hilder, M. Lezhnina, M. L. Cole, C. M. Forsyth, P. C. Junk and U. H. Kynast, J. Photochem. Photobiol., A, 2011, 217, 76-86. 
